\title{
Epidemiological Review of Macular Hole in Ekiti, Southwestern Nigeria
}

\author{
Iyiade A. Ajayi' ${ }^{1}$, Olusola J. Omotoye ${ }^{1}$, Stella Adegbehingbe ${ }^{2}$ \\ ${ }^{1}$ Department of Ophthalmology, Ekiti State University Teaching Hospital, Ado-Ekiti, Nigeria \\ ${ }^{2}$ Department of Ophthalmology, State Specialist Hospital, Akure, Nigeria \\ Email: iyiseye2005@gmail.com
}

How to cite this paper: Ajayi, I.A., Omotoye, O.J. and Adegbehingbe, S. (2020) Epidemiological Review of Macular Hole in Ekiti, Southwestern Nigeria. Open Journal of Ophthalmology, 10, 276-282. https://doi.org/10.4236/ojoph.2020.104030

Received: August 10, 2020

Accepted: November 7, 2020

Published: November 10, 2020

Copyright (c) 2020 by author(s) and Scientific Research Publishing Inc. This work is licensed under the Creative Commons Attribution International License (CC BY 4.0).

http://creativecommons.org/licenses/by/4.0/

cC (i) Open Access

\begin{abstract}
Background: Macular hole is a known cause of central visual defect with varying etiologies in different parts of the world. It was considered an untreatable condition until 1991 when varying treatment techniques began to emerge with resultant restoration of central vision. This study was carried out to evaluate the prevalence and pattern of Macular hole in a tertiary eye centre in Nigeria. Method: This is a prospective hospital-based study over a 5 year period spanning from November 2013 to October 2018. All patients with macular hole seen within this period were included in the study. Relevant data were recorded with a structured questionnaire and analysed with SPSS version 20. Results: There were 46 eyes of 42 patients which constituted about $0.5 \%$ of all new patients seen over the study period. Male to female ratio was 1:1.3 with age ranged between 15 and 91years (mean $=61.8 \pm 16.5$ years). The majority of the patients (95.7\%) had Idiopathic macular hole. Half of the patients (54.8\%) had visual acuity less than $3 / 60$ in the affected eye at the time of presentation. The majority (95.7\%) of the patients did not accept the recommended surgical treatment option because of financial incapacitation. Conclusion: Macular hole is a disease of marked visual consequence. Available treatment option is still not within the reach of the majority because of the high cost.
\end{abstract}

\section{Keywords}

Macular Hole, Southwestern Nigeria, Epidemiological Review, Central Visual Defect

\section{Introduction}

Macular hole is a defect of the foveal retina involving its full thickness from the internal limiting membrane to the outer segment of the photoreceptor layer as a 
result of macular rupture and/or tangential vitreo-retinal traction [1] [2] [3]. This condition is a major cause of central visual defect. It was considered untreatable up till 1991. Subsequently varying surgical interventional measures have emerged with remarkable visual improvement. Elderly people in the 6th and 7th decades of life have a higher incidence of the Idiopathic variety with higher occurrence among females. The prevalence varies in different parts of Nigeria. It accounted for 10 (4\%) of retinal diseases in Benin city southern Nigeria [4] and $6.6 \%$ in South-South Nigeria [5]. In other studies carried out in Southwestern Nigeria, Macular hole constituted 4.2\% - 18\% of retinal diseases seen during the study period [6] [7]. Reports on prevalence and treatment of Idiopathic macular hole in the developed world are many [1] [8] [9] [10] [11]. Studies focused on this subject are however very few in our country [5]. This could be a result of the low prevalence in the few reported studies ranging from $4 \%-18 \%$ [4] [5] [6] [7].

This study has been carried out to determine the prevalence and pattern of presentation of macular hole in a tertiary eye care facility in South-Western Nigeria.

\section{Materials and Methods}

The Ophthalmology Department of the Ekiti State University Teaching Hospital provides eye care services for the citizens of Ekiti State and its neighbouring states of Ondo, Osun and some parts of Kogi State. Details of all patients diagnosed as having Macular hole from November 2013 to October 2018 were prospectively progressively obtained. Selection criteria: All patients with full thickness defect in the foveal retina on slit lamp dilated retina examination with a $+78 \mathrm{D}$ lens regardless of age were included in this study. Demographic data were obtained for each as well as other details like duration of symptoms before presentation, laterality, history of past ocular trauma or surgery, social history, systemic and ocular comorbidities. History of alcohol consumption was also obtained. Presenting Visual acuity (PVA) and best corrected visual acuity (BCVA) were also documented. Blindness was defined based on World Health Organization standard of visual acuity less than 3/60 in the better eye with the best correction. Intraocular pressure measurements were noted. A macular hole was diagnosed by slit lamp biomicroscopy with a $+78 \mathrm{D}$ stereoscopic non-contact Volks lens after dilating the pupils with guttae phenylephrine $2.5 \%$ plus Tropicamide $1 \%$. Reports of Optical Coherence Tomography (Topcon 3D OCT-1 Maestro with spectral domain technology) were reviewed. Macular hole was classified according to the international vitreomacular traction study (IVTS) classification [1]. Data obtained were recorded and analysed using Statistical Package for Social Sciences (SPSS) version 20. Means (Standard deviations) were used to describe the distributions of continuous variables while Categorical variables were described in Percentages. Comparisons of categorical data were performed with the use of Pearson's chi-square test. $P<0.05$ was considered statistically signifi- 
cant. The study was conducted in accordance with tenets of the Helsinki Declaration. Ethical approval was obtained from the institution ethical review committee.

\section{Results}

Forty-six eyes in 42 patients presented with macular hole during the course of study. This constitutes $0.5 \%$ of the total number of 8350 new patients seen and $6.4 \%$ of 605 new cases with retinal disorders. There were 20 males and 26 females giving a Male:Female ratio of 1:1.3. The least age was 15 years while the highest was 91 years. Six cases (13.0\%) were below 40 years of age. Mean age was 61.0 years \pm 16.5 years. Idiopathic cases constituted 41 (89.1\%), 3 (6.5\%) had retinal detachment while $2(4.3 \%)$ occurred secondary to trauma. Five cases (10.9\%) were bilateral and all these bilateral cases were aged above 40 years. One patient had a past history of small incision cataract surgery with posterior chamber intraocular lens implantation with no significant visual improvement post-surgery. (See Figure 1)

$66.7 \%$ of the affected males were above 60 years of age while $80 \%$ of the females were in the age group 51 - 60 years.

History of treatment for hypertension was positive in $10(23.8 \%)$ of the patients while 2 patients were on treatment for Diabetes Mellitus. Two patients (4.8\%) honored the referral given for surgery. 44 cases (95.7\%) did not accept the option of surgery because of financial incapacitation. A report of alcohol consumption was received in $6(14.3 \%)$ while none of the cases had history of cigarette smoking. There was no significant risk of traumatic etiology among those aged below 40 years (RR 7.4 CI $0.419-145.2 \mathrm{P}=0.246$ ) however a greater risk of macular hole was observed among males under 40years of age when compared with their female counterpart (RR 2.22 CI 1.299 - 3.801 P = 0.047).

\section{Discussion}

Macular hole constituted $0.5 \%$ of the number of new patients with eye disorders in our centre during the period under study and $6.9 \%$ of new cases with retinal

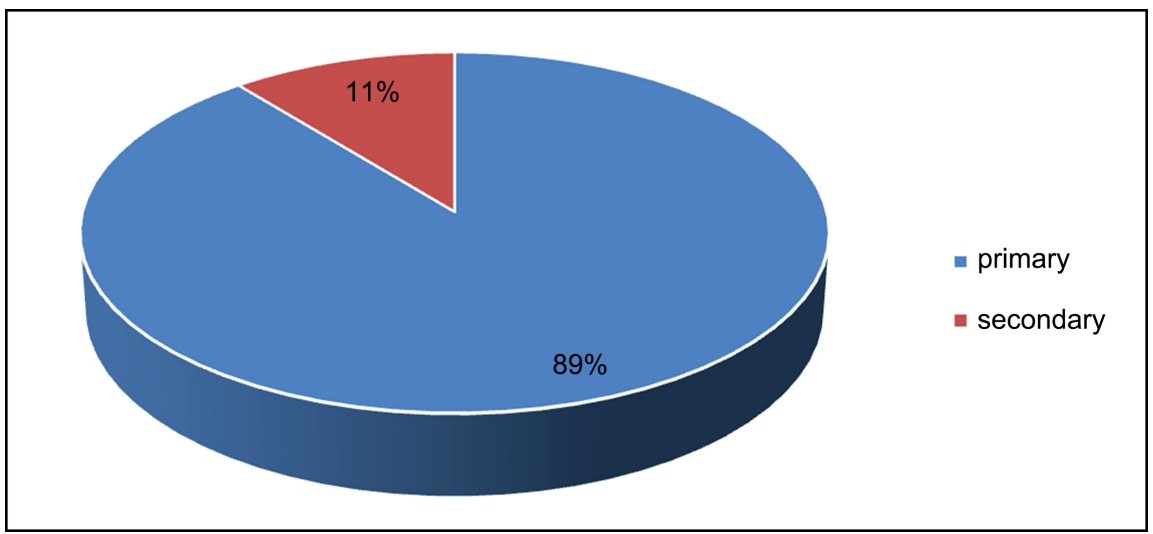

Figure 1. Types of macular hole. 
disorders. Although the age range spanned from 15 years to 91 years, a large percentage of the cases were above 40 years of age. Table 1 shows a spike in the number from 51 - 60 year age group more obvious among females. This also becomes more evident with the mean age of 61.5 years ( \pm 16.5 years). This agrees with previous reports that macular hole is a disease of the aged as elderly patients are more prone to degenerative changes and other chronic diseases of the eyes [12] [13]. This is also very close to mean age reported from a population-based study among residents of Olmsted county [9]. There was a higher ratio of females compared with males in this study. This is similar to a report by Kannan et al. [13]. It is however not as high as reported in some other studies [5] [14] [15]. A possible explanation for this may be the better health seeking behavior amongst men when compared with their female counterparts [16]. Idiopathic macular holes constituted the majority $(89.1 \%)$ of the cases. This is similar to findings in other studies across the nation and other developing and developed nations of the world [5] [9] [17]. Although traumatic macular holes were the first reported cases, Idiopathic macular hole has been opined to constitute $80 \%$ of all cases of macular hole [18]. In the patient with history of cataract surgery, the hole was discovered on examination on the first postoperative visit when it was observed that there was no significant improvement in vision. Vitreo-retinal conditions including macular hole have been found to be leading causes of blindness and low vision among elderly patients in Nigeria [4] [19]. Half of the cases presented with blindness in the affected eyes while another $45.6 \%$ presented with visual impairment (Table 2). Only minimal improvement in vision was observed with refraction among the patients. This could be explained by the absence of retinal tissue in the fovea and also in some cases the presence of sub retinal fluid with associated photoreceptor atrophy [18]. Poor vision depicts late presentation among the patients and this has been observed to be a common report among eye disease patients in developing countries like $\mathrm{Ni}$ geria [6] [7]. Primary hole constituted $89 \%$ of the cases at presentation. Hypertension was a coexisting systemic disorder in $10(23.8 \%)$ of the cases (Table 3$)$. This can also be explained by the advanced age of the majority of the cases as hypertension is a known disease of the elderly age group. Even though macular hole was initially considered a non-treatable condition, varying modalities of surgical management have evolved over the years [13] [15]. Predictors for successful surgery include good preoperative visual acuity, base diameter and minimum linear diameter as well as duration of symptoms [15]. Only two patients embraced the option of surgical treatment of the macular hole. The only patient who reported to us for follow up after surgery had a 3 Snellen's line visual acuity gain.

All others declined surgery on grounds of financial incapacitation with resultant inability to raise funds for the procedure. The major challenge of macular hole among other vitreo-retinal diseases of the retina in the developing world is the scarcity of facilities to provide this care as well as none affordability where care facilities are available [4] [6] [7] [20]. 
Table 1. Demographic characteristics of patients.

\begin{tabular}{ccc}
\hline Age Group (Years) & Male N (\%) & Female N (\%) \\
\hline $0-10$ & $1(100.0)$ & 0 \\
$11-20$ & $2(100.0)$ & 0 \\
$21-30$ & $1(50.0)$ & $1(50.0)$ \\
$31-40$ & $2(66.7)$ & $7(87.5)$ \\
$41-50$ & $1(12.5)$ & $12(80.0)$ \\
$51-60$ & $3(20.0)$ & $5(33.3)$ \\
$>60$ & $10(66.7)$ & $26(56.5)$ \\
Total & $20(43.5)$ &
\end{tabular}

Table 2. Presenting Visual Acuity (PVA) and Best Corrected Visual Acuity (BCVA) at presentation.

\begin{tabular}{ccc}
\hline Visual Acuity & PVA N (\%) & BCVA N (\%) \\
\hline$>6 / 18$ & $2(4.3)$ & $3(6.5)$ \\
$<6 / 18-6 / 60$ & $15(32.6)$ & $15(32.6)$ \\
$<6 / 60-3 / 60$ & $6(13.0)$ & $7(15.2)$ \\
$<3 / 60$ & $23(50.0)$ & $21(45.7)$ \\
\hline
\end{tabular}

Table 3. Concurrent ocular morbidity among patients.

\begin{tabular}{cc}
\hline & $\mathrm{N}(\%)$ \\
Cataract & $15(32.6)$ \\
Glaucoma & $5(10.9)$ \\
AgeRelated Macular Degeneration & $3(6.5)$ \\
Branch Retinal Vein Occlusion & $1(2.2)$ \\
Optic Atrophy & $1(2.2)$ \\
Non Proliferative Diabetic Retinopathy & $1(2.2)$ \\
\hline
\end{tabular}

As shown in Table 2, 23 cases (50.0\%) were blind at presentation. This reduced to $21(45.7 \%)$ with best correction.

Age related cataract accounted for $32.6 \%$ of ocular comorbidity as shown in Table 3 above. Only one patient out of the 2 referred reported for follow up after macular hole surgery with a 3 Snellen's line visual acuity gain.

The limitation of this study was that it was a hospital-based study hence general population applicability is limited. Sample size was also limited because it was a single-centred study.

In conclusion, Macular hole is a disease of marked visual consequence. Although a disease of the aged, the younger ones cannot be completely exonerated as observed in this study. The burden of blindness and visual impairment from Macular hole can be reduced or eliminated by early diagnosis and provision of 
subsidy for the enormous cost of treatment. This is necessary because most patients assess eye care through out of pocket expenditure except for the federal government workers who have access to the National health insurance scheme (NHIS). Among the group registered on the NHIS, macular hole surgery is not part of the treatment covered by the scheme. This implies that such surgeries can only be accessed through out of pocket expenditure. Low vision and rehabilitation services will also be required for those who are visually impaired as a result of this condition especially among those with bilateral cases and those with impaired vision in the contralateral eye from other non-treatable conditions.

\section{Conflicts of Interest}

The authors declare no conflicts of interest regarding the publication of this paper.

\section{References}

[1] Duker, J.S., Kaiser, P.K., Binder, S., Smet, D., Gaudric, A., Reichel, E., et al. (2013) The International Vitreomacular Traction Study Group Classification of Vitreomacular Adhesion, Traction, and Macular Hole. Ophthalmology, 120, 2611-2619. https://doi.org/10.1016/j.ophtha.2013.07.042

[2] Kelly, N.E. and Wendel, R.T. (1991) Vitreous Surgery for Idiopathic Macular Holes: Results of a Pilot Study. Archives of Ophthalmology, 109, 654-659. https://doi.org/10.1001/archopht.1991.01080050068031

[3] Kanski, J.J. and Bowling, B. (2011) Clinical Ophthalmology: A Systematic Approach. Saunders, Philadelphia.

[4] Uhumwangho, O. and Itina, E. (2015) Retinal Diseases in a Tertiary Hospital in Southern Nigeria. Journal of the West African College of Surgeons, 5, 1-16.

[5] Fiebai, B. and Pedro-Egbe, C.N. (2015) Managing Macular Holes in a Developing Economy. Open Journal of Ophthalmology, 5, 139-144.

https://doi.org/10.4236/ojoph.2015.53021

[6] Ajayi, I.A. (2008) Retinal Diseases in a Tertiary Hospital: The Need for Establishment of a Vitreo-Retinal Care Unit. Journal of the National Medical Association, 100, 1286-1289. https://doi.org/10.1016/S0027-9684(15)31506-6

[7] Ajayi, I.A, Omotoye, O.J., Ajite, K.O. and Ajogbasile, O.O. (2016) Retinal Disorders in a Tertiary Eye Centre in Nigeria. Pakistan Journal of Ophthalmology, 32, 152-158.

[8] Wang, S., Xu, L. and Jonas, J.B. (2006) Prevalence of Full-Thickness Macular Holes in Urban and Rural Adult Chinese: The Beijing Eye Study. American Journal of Ophthalmology, 141, 589-591. https://doi.org/10.1016/j.ajo.2005.10.021

[9] McCannel, C.A., Ensminger, J.L., Diehl, N.N. and Hodge, D.N. (2009) Population-Based Incidence of Macular Holes. Ophthalmology, 116, 1366-1369.

https://doi.org/10.1016/j.ophtha.2009.01.052

[10] Banker, A.S., Freeman, W.R., Azen, S.P. and Lai, M.Y. (1999) A Multicentered Clinical Study of Serum as Adjuvant Therapy for Surgical Treatment of Macular holes. Archives of Ophthalmology, 117, 1499-1502.

https://doi.org/10.1001/archopht.117.11.1499

[11] Stalmans, P., Benz, M.S., Gandorfer, A., Kampik, A., Girach, A., Pakola, S., et al. (2012) Enzymatic Vitreolysis with Ocriplasmin for Vitreomacular Traction and 
Macular Holes. New England Journal of Medicine, 367, 606-615. https://doi.org/10.1056/NEJMoa1110823

[12] Nwosu, S. and Onyekwe, L. (2002) Ocular Problems of the Elderly in Onithsa, Nigeria. Nigerian Journal of Clinical Practice, 5, 123-126.

[13] Kannan, N.B., Adenuga, O.O., Kumar, K. and Ramasamy, K. (2016) Outcome of 2 cc Pure Sulfur Hexafluoride Gas Tamponade for Macular Hole Surgery. BMC Ophthalmology, 16, Article No. 73. https://doi.org/10.1186/s12886-016-0254-9

[14] Huang, J., Liu, X., Wu, Z. and Sadda, S. (2010) Comparison of Full-Thickness Traumatic Macular Holes and Idiopathic Macular Holes by Optical Coherence Tomography. Graefe's Archive for Clinical and Experimental Ophthalmology, 248, 1071-1075. https://doi.org/10.1007/s00417-009-1226-Z

[15] Madi, H.A., Masri, I. and Steel, D.H. (2016) Optimal Management of Idiopathic Macular Holes. Clinical Ophthalmology (Auckland, NZ), 10, 97-116. https://doi.org/10.2147/OPTH.S96090

[16] Resnikoff, S., Pascolini, D., Etya'Ale, D., Kocur, I., Pararajasegaram, R., Pokharel, G.P., et al. (2004) Global Data on Visual Impairment in the Year 2002. Bulletin of the World Health Organization, 11, 67-115. https://doi.org/10.1076/opep.11.2.67.28158

[17] Sen, P., Bhargava, A., Vijaya, L. and George, R. (2008) Prevalence of Idiopathic Macular Hole in Adult Rural and Urban South Indian Population. Clinical \& Experimental Ophthalmology, 36, 257-260.

[18] Agarwal, A. (2011) Gass' Atlas of Macular Diseases: 2-Volume Set-Expert Consult: Online and Print. Elsevier Health Sciences, Amsterdam, 646.

[19] Olusanya, B., Onoja, G., Ibraheem, W. and Bekibele, C. (2012) Profile of Patients Presenting at a Low Vision Clinic in a Developing Country. BMC Ophthalmology, 12, Article No. 31. https://doi.org/10.1186/1471-2415-12-31

[20] Oluleye, T. and Ajaiyeoba, A. (2006) Retinal Diseases in Ibadan. Eye, 20, 1461-1463. https://doi.org/10.1038/sj.eye.6702343 